\title{
Gaps between the digits
}

\section{On the fleshy unknowns of the HUMAN}

Keywords: artificial intelligence, machine bias, black studies

Artificially intelligent systems (AI) are increasingly becoming the ubiquitous, unseen arbiters of our social, civic and familial lives. Ever increasing computational power, combined with almost limitless data, has led to a turning point in the way artificial intelligence assists, judges, and cares for humans. In the wake of such power we must ask ourselves what it is that we are making inherently unknowable as the world becomes more predictable, managed, and discrete. Building on the work of black feminists Sylvia Wynter and Hortense Spillers, I perform a reading of the "flesh". I aim to hint towards a different field of relations and a knowledge politic premised on unknowability and the radical potential of the subjugated to foster new imaginaries of the human fluid enough to weather instability. This piece troubles the boundaries inscribed between things. Settled in the flesh of blackness, we are reminded of the ways that blackness floods the landscape of productive reason while holding outlier ways of being beyond Western Man. This paper seeks to return to the pulse found within the flesh as a critical site for thinking through alternate ways of being, within the messiness, the unstable, the precarious; finding life born of transition, the pulse within discord.
I am wondering what queering the relation between the human and other forms of life, queering the relation between life and non-life, or undoing the sovereignty of relation altogether, will mean for the Black body. My inclination is to ask not what form can do to enable or open itself to queerness, but to ask whether form will let Blackness live.

-Andre Carrington, "Mike Brown's Body: New Materialism and Black Form"

The history of blackness is a testament that objects can and do resist.

-Fred Moten, "In the Break: The Aesthetics of the Black Radical Tradition"

\section{Introduction}

Consider two very different and divergent representations of an iconic feature of the American landscape, the Mississippi River. The first representation was created by J.T. Lloyd in 1862 and maps the contours of the Mississippi River as it stretches from St. Louis until it spills out into the Gulf of Mexico. Created with painstaking acuity, Lloyd claims to detail each "sugar plantation, cotton plantation, city, town, landing, sand bar, island, bluff, bayou, cut-off, steamboat channel, mileage, fortification 
and railroad line" along the river (see Figure 1). Llyod was so confident in his ability to accurately render each figure, that he includes a guarantee to any potential customer, printed in all caps and italicized stating “WARRANTED CORRECT, OR THE MONEY REFUNDED” (see Figure 1). Lloyd's map is one that is meant to convey trust to its viewer. He promises a way to literally navigate that which is immense, powerful, and overwhelming. Herein lies the power of the map as a representational image. By rendering the Mississippi River as a winding blue line, it becomes knowable. This blue line has become a commonplace icon for waterways. It assumes a sense of linearity, directionality, and discretion assuaging the anxiety of a wild raging river, a force to contend with. Containing the river in this way inherently shifts what we understand the river to be. No longer a subject that exerts effect; flooding, spreading sediment, changing direction, the river is rendered as an object upon which people extract and enact force, leveeing its edges, expanding and condensing its channels, once bespoke with reverence now succumb to the folly of control. This representation of knowability aestheticized through the form of the single linear line is a necessary precursor for the coming management and taming of the river. Geographer Clyde Woods draws our attention to the political economy of the river and the parallels between its taming and the taming of surplus labor. He writes:

Yet the promise of swift destruction posed by annual flooding required an extremely high level of coordination, study, experimentation, and infrastructure development ... The desire of planters to control both the African American majorities and the annual ravages of the region's rivers led to the creation of extremely high levels of class and ethnic solidarity between the planters and working-class Whites. The intersection of these trends marked the birth of the Delta as the superplantation region of the South (Woods 2017: 28).
In this reading, the map is never simply an aesthetic abstraction of the world into two dimensional form. Instead it is always imbricated in politics, power, differentiation, industry, and territoriality.

The second representation is one of unbridled tangles, and recursively looped waterways that flow, spread, and interrupt each other, a cacophony of effusion, a watery din. It was created in 1944 by Harold Fisk who was employed by the Army Corp of Engineers. This map charts all of the variant alluvial paths that the Mississippi River has taken over time. Rather than treating the Mississippi as a body that can be managed and relegated to a transit corridor, this map seeks to understand the evolution of the river and its many iterations over time (see Figure 2). Sourced primarily from aerial photography, Fisk's map is robust, spilling cascading colors over a muted background; it demands attention drawing the eye to the circuitous routes of flow. The river transgresses its present path of flow signified by negative space, and works as an agential body replenishing the land with silt and sediment. Fisk's map is not one of delimiting a living body as knowable. Instead, it presents the frictions inherent within the logics of the map, highlighting the spatial temporal problem of fixing. It is imbued with a liveliness that undermines the hubris of management and requires reverence. By visualizing the river in this way Fisk creates a sense of tension between that which we have come to know as discrete and linear, the blue line, and the unleveed bends of alluvial shift that exist in the excesses of interdiction. His interpretation of the data into a visual form, while accurate, deemphasizes the linearity of the river, literally showing the present path as negative space. These decisions regarding the aesthetics of representation open up the map as a meaningful form to contend with change and flux, rather than inhering within fixed relationships of time and space. It is also an invitation to linger in the space between positivist notions of empiricism and interpretive visualization. 


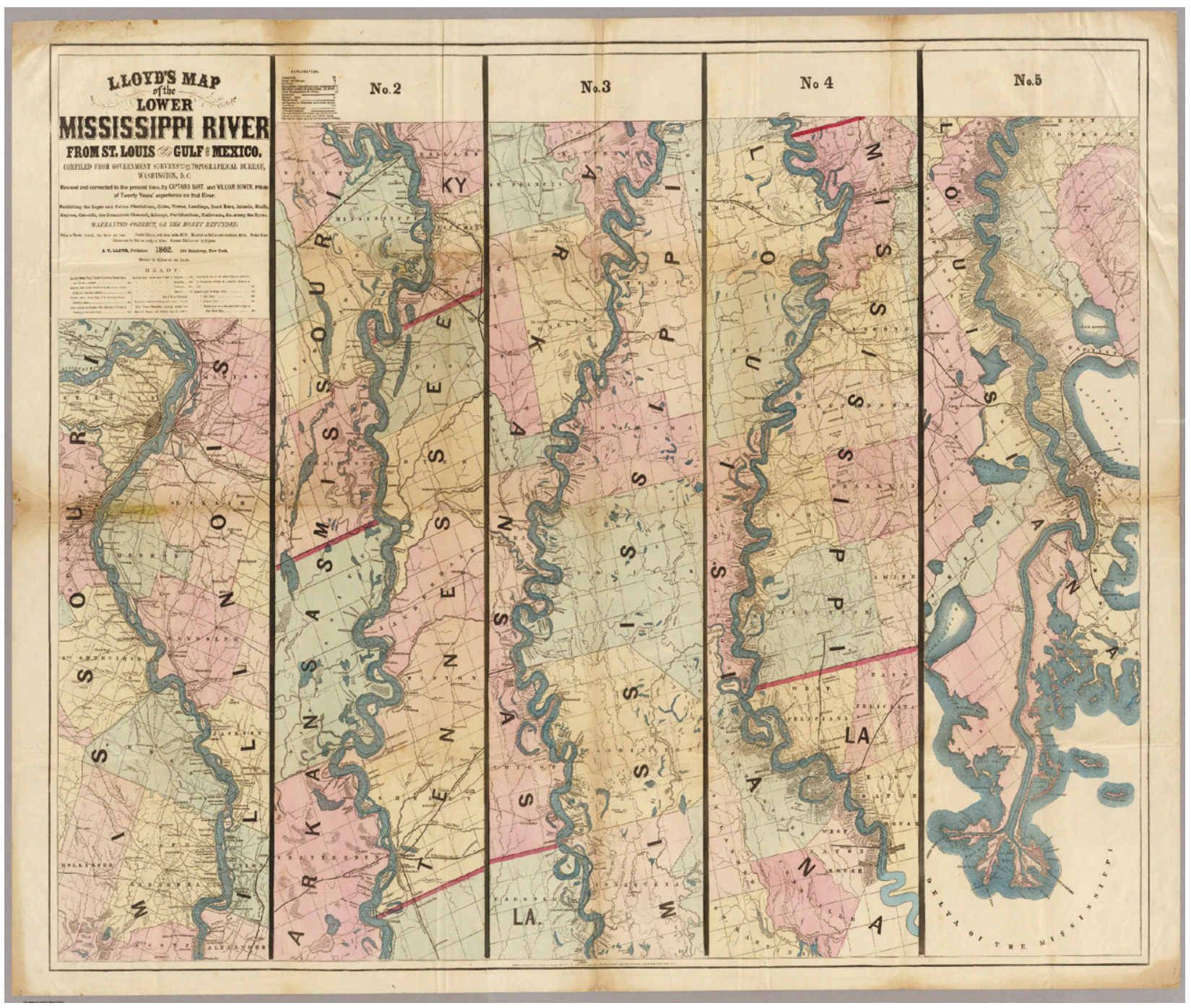

Figure 1. Lloyd's map of the Lower Mississippi River from St. Louis to the Gulf of Mexico. Lloyd, J.T.,1862. 


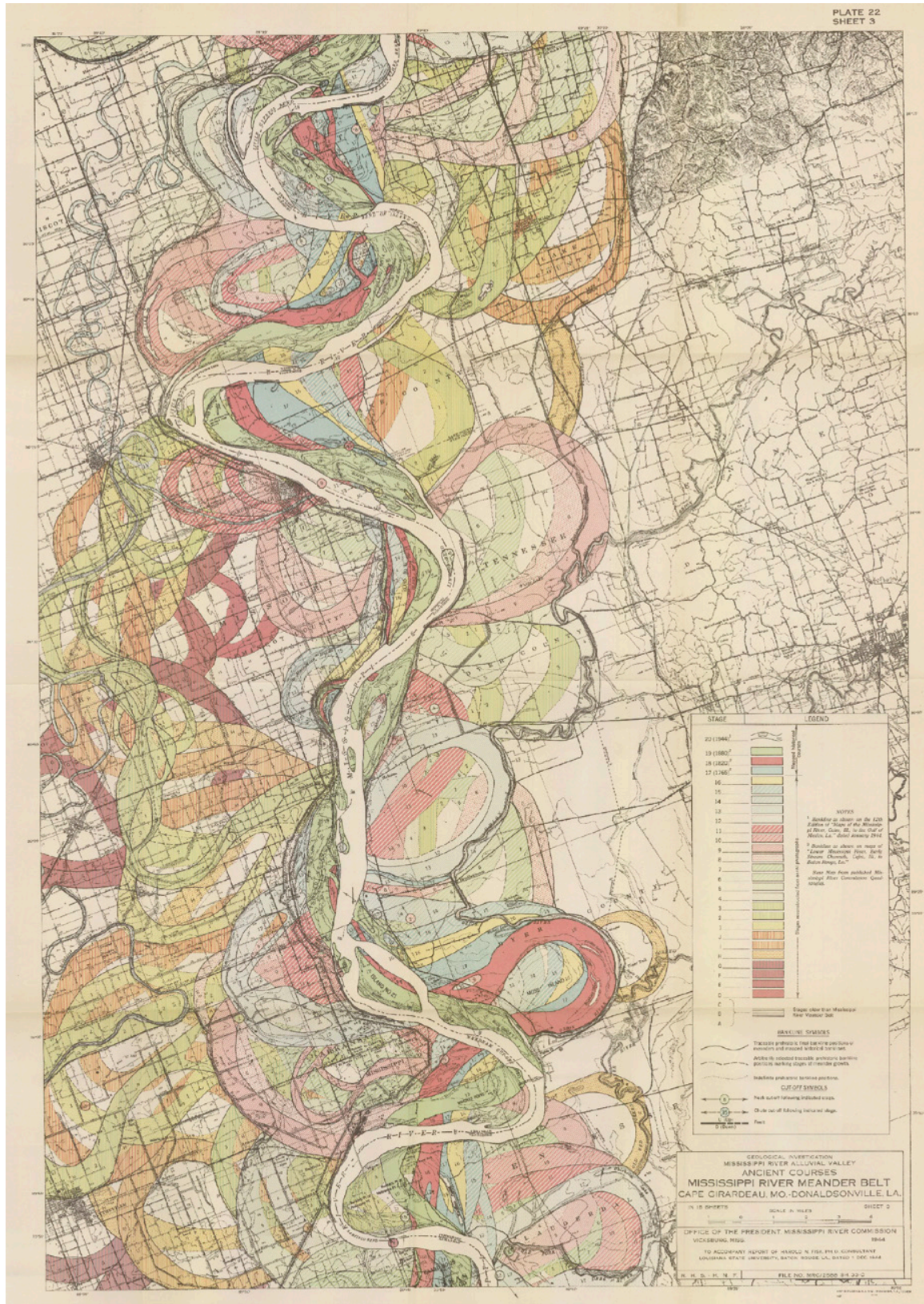

Figure 2. The Alluvial Valley of the Lower Mississippi River, Harold Fisk, 1944. 
Cultural geographer Denis Cosgrove would say that these maps are simultaneously "true representations and virtual spaces." This is not meant to deny the truth of data but to situate that truth as particular, subjective, and limited, rather than reproducible, universal, and omnipotent. Such discussions regarding truth and techniques of representation, however, are not new but perennial with each emerging technology. The map as a visual representation of truth through data streams is no different, limited in its ability to capture reality, in turn producing that which it seeks to describe.

On this point, artist and cartographer Laura Kurgan reminds us:

their basis in remotely sensed data helps us understand what has become of truth in the era of the digital data stream: it is intimately related to resolution, to measurability, to the construction of a reliable algorithm for translating between representation and reality. The fact that they are virtual images does not make them any less true, but it should make us pause and consider what we mean today by truth" (Kurgan 2013: 12-13).

This paper begins in that pause. This work contributes to scholarship that theorizes the mutual constitution of race, gender, and sexual difference by examining the ways that quantitative methods of analysis, undergirded by large scale data collection, codify difference as singular, comparative, and managed. Such approaches can only profess relevance in the subsequent effects of single issue oppression, bearing little promise for those lives not lived singularly. ${ }^{2}$ In particular, I analyze The Human Project, a big data research project run by NYU's Institute for the Interdisciplinary Study of Decision Making and the Kavli Foundation and which aims to "map the human condition". I place this project within a larger critical conversation highlighting the ways that empirical methods claim universality while reifying the differentiation upon which heteropatriarchal white supremacy depends. With a strong emphasis on approaching questions of information design through critical humanities scholarship, I hope to make a tear in the axiomatic power that empirical data purports and to trouble the ways in which design upholds such power through representational aesthetics of cleanliness, modernity, and knowability. I chart the ways that data constructs and fixes blackness to the body, and how such representations typify particular social imaginaries that justify and perpetuate violence on those same bodies. Moreover, I question the dependency of using tools of analysis, metrics, and quantification to redress such violence, asking what the limits to the visions of justice that they suggest are.

Towards that end, I offer a reading of the flesh as a critical site that troubles actuarial instruments by engaging with the violence of racialization and the excesses of knowability. Or put far more eloquently by warrior-poet theorist Audre Lorde, “The master's tools will never dismantle the master's house” (Lorde 2015: 2). This requires speculation to operate in the excesses of our current tools, past their delimiting logics. Differentiated from the body (as individual and agential), I argue for the flesh as an alluvium site of relationships that refuse to be parsed, neither self-contained or singular, but intertwined, affective, irresolute, and extimate in their connections. $^{3}$

\section{As HUMAN as an acronym}

10,000 New Yorkers, 4,00o households, 20 years, 1 research platform; solving the puzzle to a better, longer life. These are the claims that sit at the center of The HUMAN Project (Figure 3). Buttressed between the promise of big data and large scale beneficence, The Human Project is described by its team of creators as "a pioneering research platform that aims to solve the toughest 


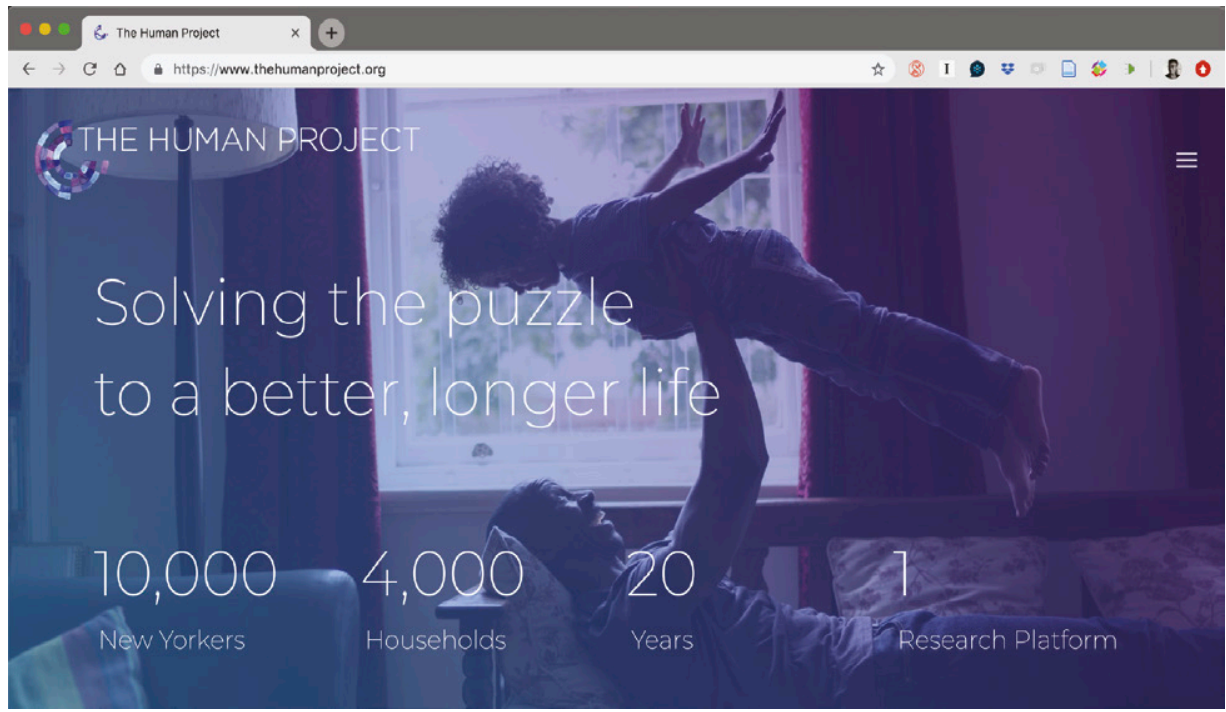

Figure 3. The HUMAN Project Homepage, https://www. thehumanproject.org/. problems we face today." The description continues, "The breakthroughs will come from seeing how the millions of invisible connections between our bodies, behavior, and the environment shape us and determine our future. Together, we can reveal the big picture to creating a better world." (“The Human Project”, 2017). In this paper, I query whose bodies count and whose behaviors matter. In short, how can we come to shape a future that does not merely replicate the attendant violence of the past?

The contours of The HUMAn Project resemble a growing body of research by which big data is crucial for shaping human behavior, making sense of complexity, and making a better (read as more technocratically controlled, predictable, and managed) world. Yet, it is the critical site of the human subject and its accordant representations within which I intervene. In this context human becomes "HUMAN", an acronym for the project meaning, Human Understanding through Measurement and Analytics. You are no longer a body. Instead "you" is simply the moving amalgam of discrete legible indicators counted and used to trade in authority, claiming the ability to "quantify the human condition". With an overemphasis on "everything" being the scope and scale of data collection, the HUMAN project is opaque in its detailing of the data types it seeks to retain, though it hints at a few possibilities. When asked about the types of data collected, The Human Project states:

This includes financial, educational, criminal justice and health records as well as information about their daily habits such as what they eat, where they go, when they sleep, how they exercise, and their patterns of communication and interaction (Frequently Asked Questions 2017).

Missing from this response is any clear indication into the sources or metrics for such data. The use of vague phrases such as "patterns of communication" obscures vital questions as to what is being collected. Are participants meant to divulge the content of personal 
conversations between family members and loved ones, or just the frequency and locations of communications exchanged?

While the HUMAN project may be the most ambitious of its kind, it is certainly not alone in its desire to organize the body into taxonomies of social definition and behavioral understanding. In their anthology "Deviant Bodies: Critical Perspectives on Difference in Science and Popular Culture", Jennifer Terry and Jacqueline Urla detail the ways the body is discursively formed through technique and method. They state:

Bodies do not exist in terms of an a priori essence, anterior to techniques and practices that are imposed upon them ... In short, bodies are points on which and from which the disciplinary power of scientific investigations and their popular appropriations is exercised. Knowable only though culture and history, they are not in any simple way natural or ever free from relations of power (Terry \& Urla 1999: 3).

Echoing Bazin's attention to the eye of the photographer in framing the "objectivity" of the camera, Terry and Urla remind us that the body itself is not a universally self-evident figure, but it is rather always discursively framed through the eye of particular investigatory techniques and culturally lodged research questions. Their work helps to situate the body of the HUMAN project as a compilation of particular choices, assumptions, and protocols inherent in both the researchers, their instruments of measure, and the institutions sponsoring the project. Through the machinations of the HUMAN project, the body becomes known through the data streams that it generates, limited by what can be counted and collected. By reading Bazin, Terry, and Urla, together the body of the HUMAN project is defined by the quantitative techniques and modes of analysis that the project's researchers undertake, and implicates them in the constructive process of giving that body form.

I situate the HUMAN project as a provocation to consider the limits of what can be made knowable through dependencies on quantifiable data. Entering through the project's namesake, I strip away attenuated layers searching for the body of a human situated in the elsewhere of another time. Centering the flesh of blackness, I outline the ways that black construction is always positioned as the outlier upon which significations of the human are dependent. This ontological paradox opens the possibilities for the flesh to meaningfully engage with unknowability. Contrasted with uncertainty, the following sections trace the contradictions, productive tensions, and connections between blackness, flesh, and data sets needed to emerge differently situated upon fertile soil.

\section{Fixing logics: Building the set}

How might we go about thinking and living enfleshment otherwise so as to usher in different genres of the human and how might we accomplish this task through the critical project of black studies? (Weheliye 2014:3).

This is the question that sits at the core of Weheliye's work, "Habeas Viscus: Racializing Assemblages, Biolpolitics, and Black Feminist Theories of the Human", and drives the depth and nuance of his engagements with theorizing the human. Weheliye points to the critical ways in which the human of modern western nations (read classically as Man) has always been imbued in the ongoing violence of individuation yielding a highly particularized and operationalized human. Pointing to the central role of racialization in shaping such particularities, Weheliye writes:

Overall I construe race, racialization, and racial identities as ongoing sets of political relations that 
require, through constant perpetuation via institutions, discourses, practices, desires, infrastructures, languages, technologies, sciences, economics, dreams, and cultural artifacts, the baring of nonwhite subjects from the category of the human as it is performed in the modern west" (Weheliye 2014: 3).

In this quote Weheliye complements Terry and Urla's work on the body by arguing that "human" has never been a neutral or axiomatic category, but instead it has always been ensnared by, and articulated through the powers of discourse.

Building on the work of black feminists Sylvia Wynter and Hortense Spillers, Weheliye is deliberate in his use of racialization noting that the racializing and fixing of blackness as aberrant and non-normative is never free from its correlative gender and sexual constitutions. Put simply, it is through the process of racialization that blackness, gender, and sexuality are contained within a field of relational deviance, not able to be parsed or neatly separated, i.e. racialized gender. Racialization and its corresponding depravation of gender and sexuality discipline humanity into categories of full humans, not-quite-humans, and non-humans. Understanding the central necessity of racialization to birth the containment of the human as cis white straight able bodied and male, black feminist studies become uniquely positioned as a "substantial critique of western modernity and a sizeable archive of social, political, and cultural alternatives" (Weheliye 2014: 3).

For Weheliye, black studies operate as a particular mode of knowledge production, carefully distinguishing between what Spillers calls "real objects" and "objects of knowledge" (Spillers 1994: 65). According to Spillers, the crisis within black studies lies in its misreading as theorizing from the radical particularity of blackness. Spillers works to disambiguate the real object, that which is naturalized, from objects of knowledge, those which are formed through the complex interplay among institutions, politics, violence, discourses, practices, and economics. In this postulation, black people are not the real objects of black studies, rather blackness as the outcome of racialization becomes an object of knowledge. To misread black people as the real objects of black studies naturalizes race as a modality of either biology or culture, and elides the false universalism of Man by which black people become nonhuman. If the human becomes an object of knowledge within black studies, it can no longer be relegated to the particularism of black bodies. Instead, this positions race as a general theory and critique of western modernity and its divisive enshrining of humanity, by which to discipline others is seen as unfit. Put simply by Weheliye when evoking Wynter, "Our issue is not the issue of race, our issue is the issue of the genre of Man. It is the issue of Man that causes all the -isms." (Wynter 1999). Consistent with the larger work of black feminist epistemology, Wynter and Spillers understand that the foundation for the critique of Man cannot be isolated into a single form of subjection (black or female), but must point to complex interlocking oppressions that uphold the problematic equating of Man to humanity. Making clear the centrality of their arguments to his insistence on black studies, Weheliye writes:

For Wynter, a feminism that does not aspire to create a different code for what it means to be human merely sketches a different map of Man's territorializing assemblages; however in order to abolish these assemblages feminism's insurrection must sabotage its own prescribed role in the empirical articulation of its representations in effect by coming out of the closet, moving out of our assigned categories (Weheliye 2014: 27).

This passage calls for a reformulation of the category of human. For Wynter, however, it is not enough to carve out a new space within the category of Man, and 
he demands the very category itself to be dismantled and stripped from its founding logics within white male embodiment. Attention should also be paid to the spatial metaphors present in Weheliye's evoking of Wynter.

Wynter describes the position of Man as territorializing, one that not only defines space but controls, borders, and manages it. In this case Man becomes the managerial authority over its own differentially allocated privileges. Wynter incisively understands that this practice of defining space is always imbricated in a comparative analytic based on differentiation that justifies full, partial, and excluded access to the category of human. This practice is not only a comparative one, but also one that requires a vigilant adherence to its logics which "rationally" allocate such access to qualifying subjects. This is emphasized by Wynter's call for feminism to "sabotage its own prescribed role in the empirical articulation of its representations ... moving out of our assigned categories." Here Wynter begins to hint at an emerging method for a new politic that in the words of Aime Cesaire births "a true humanism made to the measure of the world."

Bringing to bear not just the operationalizing of black studies as a global analytic for critique, Weheliye turns our attention to the promise black studies holds to craft, what Fanon calls "the real leap which consists of introducing invention into life" (Fanon 1968: 229). By this Fanon means that the radical tradition of black studies lies in the liminality and incongruence of the black subject within western modernity. Blackness as an object of knowledge, because of its unassimilability, rather than in spite of it, allows for the radical potential of a different set of political imaginaries that forge different humans of humanity. This potential materializes in Spillers' concept of "the flesh". In her seminal essay "Mama's Baby, Papa's Maybe", Spillers details the ways in which the bodies of black slaves were removed from their corporeal agency and relegated to what she calls the flesh. This transition from body to flesh allows for the undistinguished process of fungibility, in which no longer embodied, enslaved black people became a raw material. Spillers is careful to explain that flesh, while it may be antecedent to the body, is not a biological occurrence but requires the elaborate apparatus of constitutive violence through "the calculated work of iron, whips, chains, knives, the canine patrol, the bullet" (Spillers 1987: 64). Flesh operates not only outside of a body but in a strange hybridity not quite human, not quite inanimate but outside of humanity marked by Man. Evincing theorists such as Maurice Merleau-Ponty and Elizabeth Grosz in conversation with Spillers' flesh, Weheliye notes the radical potential within the position of the flesh. He writes:

Conceptualized in this way, the flesh thus operates as a vestibular gash in the armor of Man, simultaneously a tool of dehumanization and a relational vestibule to alternate ways of being ... Not an aberration, yet excluded, not at the center of being but nevertheless constitutive of it (Weheliye 2014: 44).

\section{Following Weheliye allows for the articulating} of crucial analytical tools, real objects versus objects of knowledge, as well as the potential path of an alternate radical imaginary of the human found in the liminal spaces of Spillers' flesh.

\section{Racializing assemblages: Making through discretion}

The implicit biases and attenuating violence of machine learning and big data aggregation have emerged as pivotal contributions to critical data studies (O'Neil 2018; Noble 2018; Eubanks 2018). Through wide ranging concerns from data protection and privacy, to the racialized coding of data, to the propriety opacity of algorithms themselves, it cannot be understated that these concerns will be paramount in addressing new articulations of 
digital rights, legal recourse, and regulation. Yet, despite such concerns and gaps in governing protocol, the deployment of such technical applications are growing in both their ubiquity and authority as adjudicating bodies over the quality of lives lived and the authoring of space (AI Now Institute 2018). Understandably so, this asymmetry has sparked outcry and coordinated pushes for legal protection and regulation. These responses are essential first steps in curtailing the power of algorithms and the increasingly concentrated corporate entities that own their intellectual property. However, I want to turn my attention to the longue durée of considering how such applications embodied by the HUMAN project work to actively define and enclose particular understandings of the human entrenched in social antagonisms of race, gender, and sexuality.

To give credence to the magnitude of its claims to quantify the human condition as a whole, measurability becomes the single most important factor of being human according to The HUMAN Project. Because quantifiable data collection is the primary methodology used by the project, it is dependent on creating indicators and proxies that are numerical. Therefore researchers are concerned only with the aspects of human nature that they can count and process. Within the processing of information extracted from the point of the body, there is an eerily reminiscent parallel with the ways that Spillers theorizes the making of the flesh. In the essentializing of blackness to the slave subject, stripped of any agency even over one's body, the flesh must be extracted from the body as a continuous raw material to be mined and made fungible. While it is crucial to note that the body becomes somewhat immaterial in this context, the violence that gives shape to the flesh are wholly material and unrelenting in their exactness. However, in the articulations of the human crystalized but certainly not originated by the HUMAN project, the materiality of the body as a contained vessel of self-determination under
Western liberal subjectivity is challenged. Increasingly, the body (assumed as human) becomes a fungible site for the enclosing and extracting of information, paramount as a chief commodity within late global capitalism.

The promotional materials of the HUMAN project consistently use collective pronouns such as "us" and "we", often to describe the vision of the project as one that is communal, and an affront to more corporatized forms of data extraction and brokering. Project Director, Paul Glimcher says:

The Kavli HUMAN project offers each of us this challenge, take your data back. Instead of giving our data to corporations let's bring our data together as a community. Let's use that data not to sell things but to make a better world (The Human Project 2017).

Glimcher mildly attempts to distinguish the intentions of the project as being different from those of corporate interest in reductively stating that the data is to be used to make a better world, not sell things. However, the qualifying and grounding of such a world rarely materializes. Instead, such opacity masks a utilitarian belief that if enough data is collected and correlated the need for analysis becomes defunct (Mattern 2018). It is this intended opacity of a better benign world that constantly drives the extractive ethos of capitalism, collection at all costs, at the promise of large scale solutionism from ending poverty to combating climate change. This belief in the techno utopian extends a docile participation of willing subjects by dislocating the purported benefits into an uncharted time and place of the future, looming on the horizon but always conveniently out of reach.

Weheliye's recalling of the assemblage via Deleuze and Guattari serves as a helpful framework for untangling some of the transversal nature of agency, bodies, and extraction mentioned previously. In the tradition of Deleuze and Guattari, assemblage has come to denote, 
"continuously shifting relational totalities comprised of spasmodic networks between different entities (content) and their articulation within "acts and statement" (expression)" (Weheliye 2014: 46). Following Weheliye's emphasis on racialization as a primary assemblage through which the modern western human is crafted, I want to stretch Deleuze and Guattari's concept of the assemblage to better understand how the atomizing of the body into data is indeed a process of racialization.

In parallel to early forms of scientific racism and the markings of race on the body, the quantified self takes what is assumably stable, discrete, and apparent, and crafts qualifications that are fixed to such markers. From this position the logic is to assume what is, rather than ask how things come to be or are in a state of becoming. Following the investigative reporting of ProPublic in their series "Machine Bias", researchers found grave racial imbalances in the algorithms used to predict future criminality and allocate criminal sentences. According to researchers, on average scores of risk were skewed higher for black defendants than for white defendants. The reason they give is that other indicators such as credit score, income, residential zip code, level of education, and other factors can yield compounded risk and longer sentences for black defendants regardless of whether or not they are first time or repeat offenders (Angwin et al. 2016). The logic of the algorithm assumes these indicators as real objects rather than objects of knowledge and is then incapable of understanding how systemic racism can itself color the data. The work of numerous critical race theorists, sociologists, and historians have been crucial in showing the ways that laws, urban policies, social attitudes, media, values, and institutions have shaped uneven life chances for racialized people made legible in the same indicators of credit score, income, zip code, and level of education (Oliver \& Shapiro 1995; Rothstein 2017). While it is the history of systemic racism operationalized largely through institutions and law that yields such unfavorable conditions, these disparities are affixed to the individual as indicative of that individual's future criminality. Through this assemblage of representing the self by its direct and relative coding in data, such algorithmic processing is essentialist in its racializing of the data generated from the body that then directs outcomes and possibilities for the body it has virtually come to represent. Here, Denis Cosgrove's words regarding truth, representation, and virtuality become hauntingly clear.

This process of generating racially marked data from the body to determine future outcomes aligns with what Spillers calls the "hieroglyphics of the flesh" (Spillers 1987). The hieroglyphics of the flesh represent the continuing ways in which the flesh becomes affixed to various semiotics of deviance, threat, risk, and aberration. In short, it is the making of blackness as the slave. Spillers is careful to note that the enslaved black, captive flesh, is never freed from these markings but that they continue as a constantly emergent semiotic both consciously and unconsciously recognized. Similarly, data, representative of the racial fixing of risk and abjection, are affixed to and simultaneously become representative of the body under the provocation of the HUMAN project. What parity then can be found in the decision making of the machine when dependent on privileging data as self-evident, eliding how it comes to be?

\section{Building from detritus: Towards fleshy ways of unknowing}

By reviewing the flesh in this way, the vital contributions of real objects, objects of knowledge, and racializing assemblages offer rich material towards engaging the issues and concerns present in the HUMAN project. By reviewing them I hope to ultimately hint at a leap of invention into life that I am calling the fleshy ways of unknowing. Weheliye, via Spillers and Wynter, is 
adamant in determining the human as an object of knowledge, freed from its naturalization as an ahistopolitical figure. In a contemporary age where there are sizable attempts to make the world more measurable, familiar, and predictable, it seems pertinent to consider the episteme of data itself as a coterminous object of knowledge alongside the human.

By treating data as objects of knowledge, we become tasked with understanding the boundaries and contours of what counts as data, making explicit what can be contained and toward what purpose, as well as what evades and lives only in surplus of the discursive bounds of data. It is this surplus that evades the containment of phenomena to data, that figures as the fleshy ways of unknowing. Weheliye, by way of Spillers, positions the flesh as a crucial point of departure in thinking through different possibilities of the human free from the normative containment of Man. On this point, Weheliye asks:

When the hieroglyphics of the flesh are construed not merely as banishments but as transit visas to universes betwixt and between the jurisdictions of Man, they prompt the following question: how is it possible to politicize the natural sweetness of the flesh without the limits imposed by the concepts of bare life and biopolitics? (Weheliye 2014: 127).

Weheliye goes on to envision the flesh as a kind of ether that is used to both simultaneously constitute Man while also standing outside of it. This dual placement holds a vantage position to then consider the range of scope, of lives lived outside the encapsulation of Man, and equally important the epistemologies that are born from the flesh.

I now want to reflect on my own project Decoding Possibilities, a collaboration with researcher and scholar Treva Ellison. Decoding Possibilities is a counter mapping project that intervenes in the narratives and spatial imaginaries born from axiomatic data. Decoding Possibilities deals specifically with the legacy of redlining within American cities. Redlining was a process that equated racial census data of where black people lived with risk, and systematically restricted access to home ownership, fixing radicalized bodies to enclosed urban spaces of dispossession. In the shadow of this ongoing injustice, there have been numerous digital humanities projects that seek to highlight this violence by mapping the effects of redlining using original Holc (Home Owners' Loan Corporation) maps and contemporary census data. ${ }^{5}$ While meaningfully trying to redress social, economic, and political racial violence these projects often reify equations of blackness to abjection by eliding the histories of grounded responses to redlining. Black geographer Katherine McKittrick captures this peril trenchantly stating:

Many analyses of racial and spatial violence rely heavily on describing and re-describing spaces of absolute otherness as well as the inhabitants of these spaces of otherness ... It logically follows, because they are dead and dying, the condemned and 'without' apparently have nothing to contribute to our broader intellectual project of ethically reimagining our ecocidal and genocidal world (McKittrick 2011: 955).

Decoding Possibilities centers the work of queer black feminist activists, The Combahee River Collection, as they navigated the racilaized spaces of Boston to launch a self-defense campaign in response to the unanswered murder of 11 black women in 1979. The intellectual forbearers of intersectionality, Combahee understood their oppression as queer black women to be interlocking and co-constituted along lines of race, gender, and sexuality rather than singularly defined. Put succinctly, their lives were not single issued and could not be parsed neatly. As a result, their navigations of 
space bridged across various strategic and unlikely allies, making connections between white feminist organizations in Cambridge and black nationalists in Dorchester and Roxbury. This intersectional spatial imaginary crafted overlapping and circuitous routes throughout the city reminiscent of Fisk's alluvial maps. Using Fisk as an inspiration, we began mapping the paths that Combahee took in forging their campaign, uncovering the fertile lands left in the wake of formerly redlined areas. This project called for stretching the aesthetic rules of cartographic design premised on axiomatic legibility and cleanliness. Instead, we chose to show the tensions in the map between the spatial imaginary borne from Combahee and the abjection narratives of redlining. In doing so we settled on a $\mathrm{f}(\mathrm{r})$ ictional interface that superimposed the contours of the redlined areas of Boston over the map obscuring the ground underneath, rendering the land unknowable (see Figure 4). Underneath, printed in semi-transparent cyan color, were the alluvial routes of the Combahee River Collective.

This work makes the case that if we continue to redress racial violence only through empirical tools, we actually lose sight of the land and the alternate knowledges that it holds. The alluvial flows undertaken by Combahee are an example of flesh in motion. Rather than operating as a self-contained entity with a brick and mortar home, Combahee forged connections along differential lines of race, gender, and sexuality. This ability to directly address the violence of differentiation as a precursor for forming alliances aligns with the same black feminist scholarship from which the flesh and intersectionality are conceived. However, such contributions fall outside the bounds of knowability within the discrete, self-evident, and comparative logics of big data projects such as the HUMAN project or J.T. Lloyd's mapping of the Mississippi.

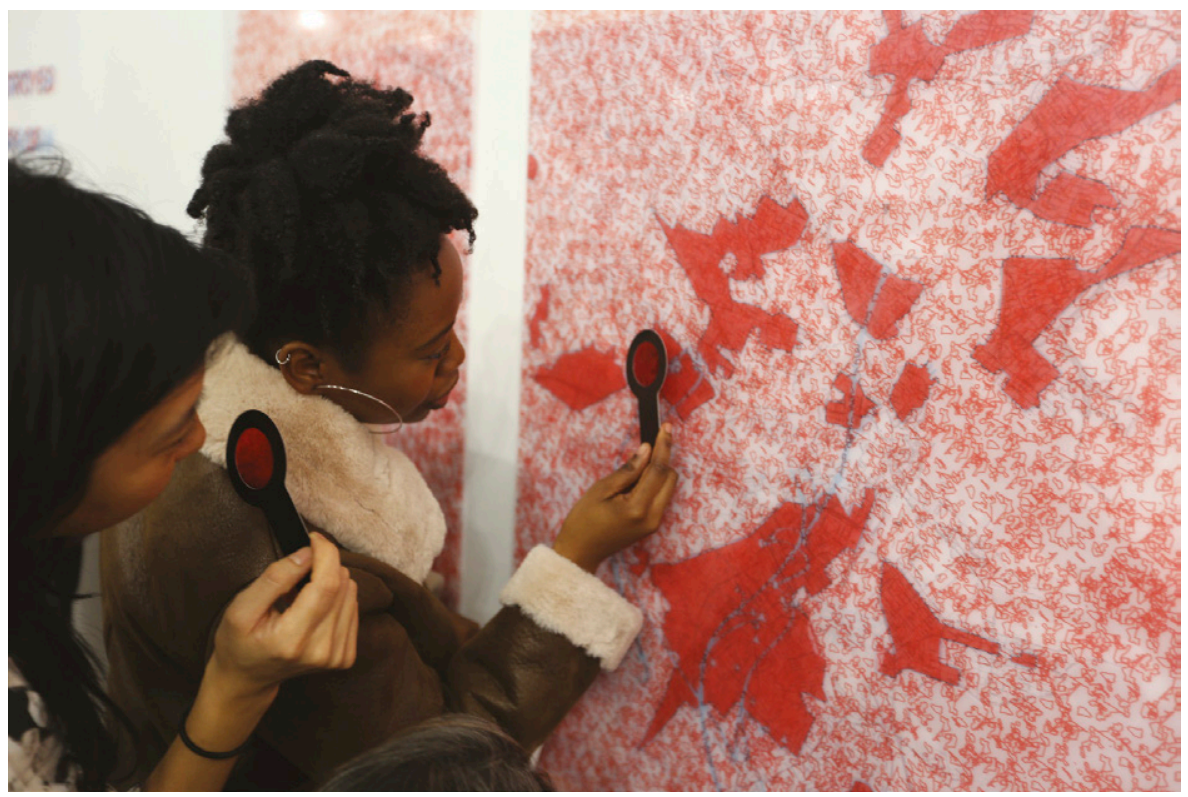

Figure 4. Decoding

Possibilities, Romi Ron

Morrison + Treva Elllison, 2017. 
The flesh reminds us of the potential in the fissure, navigating the gulf between Man and abjection in which life can still be lived. This gap highlights the fleshy ways of unknowing that exist before enclosure, and persist to operate in the interstices after the dataset is made. While this paper admittedly presents more questions than answers, it is a call to us all in focusing our attention on the poetics of knowing, that may not be universally transferable or modular, but which thrive in the excesses and require an engagement with the fleshy, multitudinal, alluvial, and intersectional. The goal of such a call is not to supplant any utility of quantification, but instead to consider the unknowable as a political imaginary from which to recontextualize alternate ways of living and knowing as human. It would also be unfair to situate unknowability as a promotion of ignorance or an impossibility of understanding. For me, fleshy unknowability denotes a hesitance to claim; it evokes a different field of relations which decenters the western modern subject entrenched in rationality and governance of domination over others. The fleshy unknowable operates as a reminder that Western productive reason and an overemphasis on data collection is but a particular form of knowledge. It is a form with limits and obfuscations that arises out of a distinct genealogy tethered to post-Enlightenment European individuation. Fleshy unknowability is a reminder that correcting machine bias and algorithmic violence is more than a question of technical fixes and morality training. It is a reminder of the importance of the outlier demands in redressing the frame of analysis. It is a reminder of the affective attachments that flood the gaps between digits. It is a reminder that some things are not able to be parsed but can only exist in the overlap of alluvial flows, forged through relationship. Let us leap into fleshy unknowability to sense multiple positions of life and humanity that mark the ruptures within the logics of data as axiomatic authority and human as Man, towards a liberatory, messy, ephemeral relational form of being. To inhabit the flesh as a way of living and knowing then becomes an act of refusal. A challenge to the neutrality of productive reason, it requires a fearlessness, falling in love with the world while living in the contradictions of its heartbreak, poised to leap into invention.

\section{Submission date: 4 February, 2019 \\ Accepted date: 26 July, 2019}

\section{Notes}

1. This comes from Cosgrove's influential work, Apollo's eye: A cartographic genealogy of the Earth in the estern imagination.

2. Here I reference a quote from Audre Lorde's 1982 lecture, Learning from the 6o's in which she states, "There is no such thing as a single-issue struggle because we do not live single-issue lives. Malcolm knew this. Martin Luther King, Jr. knew this. Our struggles are particular, but we are not alone."

3. Akin to Elizabeth Povinelli's adaptation from Lacan, I am using the term 'extimate' to mean a differentially entangled existence, as detailed in Horizons and Frontiers, Late Liberal Territoriality, and Toxic Habitats in e-flux magazine.

4. As first articulated in 'Culture and Colonization'. Translated by Brent Hayes Edwards. 1956. Reprint, Social Text (2010), 28(2(103)): 127-144.

5. For more information visit the project Mapping Inequality which can be found at https://dsl.richmond.edu/panorama/ redlining/

\section{References}

AI Now Institute (2018). Litigating algorithms: Challenging government use of algorithmic decision systems (Report, in collaboration with Center on Race, Inequality, and the Law, Electronic Frontier Foundation).

Angwin, J., Larson, J., Mattu, S., \& Kirchner, L. (2016). Machine Bias. ProPublica. Retrieved from www.propublica.org/article/ machine-bias-risk-assessments-in-criminal-sentencing 
Eubanks, V. (2018). Automating inequality: How high-tech tools profile, police, and punish the poor. New York, NY: St. Martin's Press.

Fanon, F. (1968). Black skin, white masks. New York, NY: Grove Press.

Frequently Asked Questions (2017, December 15). Retrieved from https://www.thehumanproject.org/faq/

Kurgan, L. (2013). Close up at a distance: Mapping, technology, and politics. Brooklyn, NY: Zone Books.

Lorde, A. (2015). Sister outsider: Essays and speeches. Berkeley, CA: Crossing Press.

Mattern, S. (2018). Databodies in Codespace. Places Journal. https://doi.org/10.22269/180417

Mckittrick, K. (2011). On plantations, prisons, and a black sense of place. Social \& Cultural Geography, 12(8), 947-963. https://doi.org/10.1080/14649365.2011.624280

Noble, S. U. (2018). Algorithms of oppression: How search engines reinforce racism. New York, NY: New York University Press.

Oliver, M. L., \& Shapiro, T. M. (1995). Black wealth/white wealth: A new perspective on racial inequality. New York, NY: Routledge.

O'Neil, C. (2018). Weapons of math destruction: How big data increases inequality and threatens democracy. London: Penguin Books.

Rothstein, R. (2017). The color of law: A forgotten history of how our government segregated America. New York, NY: Liveright Publishing Corporation.

Spillers, H. J. (1987). Mama's baby, Papa's maybe: An American grammar book. Diacritics, 17(2), 64-81. https://doi.org/10.2307/464747

Spillers, H. J. (1994). The crisis of the negro intellectual: A postdate. Boundary 2, 21(3), 65-116. https://doi.org/10.2307/303601
Terry, J., \& Urla, J. (Eds.). (1999). Deviant bodies: Critical perspectives on difference in science and popular culture. Bloomington: Indiana University Press.

The Human Project (2017, November 20). Retrieved from http://www.thehumanproject.org/

Weheliye, A. G. (2014). Habeas viscus: Racializing assemblages, biopolitics, and black feminist theories of the human. Durham: Duke University Press.

Woods, C. (2017). Development arrested: The blues and plantation power in the Mississippi delta. Brooklyn, NY: Verso.

Wynter, S. (1999). ProudFlesh: New Afrikan Journal of Culture, Politics and Consciousness (online).

\section{About the author}

Romi Ron Morrison is an interdisciplinary designer, artist, and researcher working across the fields of critical data studies, black feminist praxis, and cultural geography. Focusing on boundaries, social infrastructure, and community technology, their practice investigates cartographies of ancestral intelligence, unassimilable data, algorithmic violence, and blackness. They have had work exhibited at the American Institute of Architects New York, UN World Urban Forum, Tribeca Film Festival, Museum of Contemporary Art Chicago, Joan Mitchell Center, Recess Assembly Gallery, and Project Row Houses. They are currently an Annenberg PhD Fellow in the School of Cinematic Arts at USC in Los Angeles.

Email: morro52@usc.edu 